\title{
Decreased expression of the type III TGF- $\beta$ receptor enhances metastasis and invasion in hepatocellullar carcinoma progression
}

\author{
SEN ZHANG, WU-YI SUN, JING-JING WU, YUAN-JING GU and WEI WEI \\ Institute of Clinical Pharmacology, Anhui Medical University, Key Laboratory of Anti-inflammatory \\ and Immune Medicine of the Chinese Education Ministry, Anhui Collaborative Innovation Center \\ of Anti-inflammatory and Immune Medicine, Hefei, Anhui 230032, P.R. China
}

Received November 18, 2015; Accepted December 23, 2015

DOI: $10.3892 /$ or.2016.4615

\begin{abstract}
The transforming growth factor $\beta$ (TGF- $\beta$ ) superfamily of cytokines is multifunctional and involved in the regulation of cell growth and differentiation. TGF- $\beta$ can induce an epithelial-mesenchymal transition (EMT) of both epithelial and endothelial cells. This has consequences for cancer progression in regards to both migration and invasion abilities. The type III TGF- $\beta$ receptor (T $\beta$ RIII) is a ubiquitously expressed TGF- $\beta$ co-receptor which regulates TGF- $\beta$ signaling and the progression of various types of cancer. Previous studies have shown that T $\beta$ RIII exhibits abnormal expression and plays an essential role in regulating cancer invasion and metastasis, while little is known in regards to its role in hepatocellular carcinoma (HCC) progression. In the present study, we designed the present research to study the role of T $\beta$ RIII in the invasion and metastasis of HCC and the possible mechanisms involved. The results demonstrated decreased expression of T $\beta$ RIII in HCC patient tissues and human HCC cell lines. TGF- $\beta 1$ stimulation led to the increased migratory ability and reduced expression of T $\beta$ RIII in HCC cells. In addition, knockdown of T $\beta$ RIII by small interfering RNA (siRNA) promoted the migration and invasion of HCC cells and induced activation of the Smad 2 and Akt pathways. All the results suggest that T $\beta$ RIII is a novel suppressor of HCC progression.
\end{abstract}

\section{Introduction}

Hepatocellular carcinoma (HCC) represents the most common type of primary liver cancer (1). HCC is a highly prevalent and

Correspondence to: Dr Wu-Yi Sun or Professor Wei Wei, Institute of Clinical Pharmacology, Anhui Medical University, Key Laboratory of Anti-inflammatory and Immune Medicine of the Chinese Education Ministry, Anhui Collaborative Innovation Center of Anti-inflammatory and Immune Medicine, Hefei, Anhui 230032, P.R. China

E-mail: sunwuyi51@126.com

E-mail: wwei@ahmu.edu.cn

Key words: hepatocellular carcinoma, TGF- $\beta 1$, type III TGF- $\beta$ receptor, metastasis, invasion lethal neoplasia, and the management of HCC has significantly improved during the last few years (2). A better understanding of the pathogenesis and the molecular mechanisms facilitate a better prediction of prognosis and the most appropriate treatment approach. At present, curative therapies including resection and transplantation have increased the survival rate of HCC patients at an early stage, while those diagnosed at intermediate and advanced stages still suffered from a high risk of side-effects (3-5). Investigation of the cellular origins and the early molecular events resulting in HCC are urgently necessary for further understanding HCC disease progression.

The transforming growth factor $\beta$ (TGF- $\beta$ ) superfamily of cytokines is composed of TGF- $\beta$ s, activins, inhibins, bone morphogenetic proteins (BMPs) and anti-Müllerian hormone (AMH) and are expressed in all multicellular organisms (6). In mammals, the TGF- $\beta$ family exerts regulatory functions on cell growth, differentiation, apoptosis, immunity, extracellular matrix (ECM) production, adhesion and even embryonic development. Alterations of the components of the TGF- $\beta$ signaling pathway and abnormal production of TGF- $\beta$ s are often observed in disease progression despite the involvement in the maintenance of tissue homeostasis under both normal and dynamic conditions $(7,8)$. The TGF- $\beta$ isoforms (TGF- $\beta 1-3$ ) exert their biological effects by binding to three receptors: type I (T $\beta$ RI), type II (T $\beta$ RII) and type II (T $\beta$ RIII). Once bound to TGF- $\beta$, the constitutively active T $\beta$ RII recruits, binds and activates T $\beta$ RI, thereby stimulating its protein kinase activity. The downstream substrates for T $\beta R I$ are members of the receptor-activated Smads (R-Smads), namely Smad2 and Smad3. After inducing phosphorylation by receptors, R-Smads form complexes with common mediated Smad4 (Co-Smad), and then translocate to the nucleus where regulation of the transcription of certain genes occurs in cooperation with other transcription factors (9)

T $\beta$ RIII is the most abundantly expressed and characterized TGF- $\beta$ receptor, and is a proteoglycan comprised of 851 amino acids $(10,11)$. As a TGF- $\beta$ superfamily co-receptor, the role of T $\beta$ RIII in regulating TGF- $\beta$ signaling is context-dependent and complex $(12,13)$. The significant and indispensable role of T $\beta$ RIII in mediating signaling is exerted dependently through T $\beta R I I$ and T $\beta$ RI as well as potential signaling independently through T $\beta$ RII and T $\beta$ I. Overexpression of T $\beta$ RIII was found to restore TGF- $\beta 1$ sensitivity in CAL-27 human oral squamous 
cells (14). In MDA-MB-231 human breast cancer cells, T $\beta$ RIII expression inhibited Smad2/3 signaling dependent on the T $\beta$ RIII cytoplasmic domain, and the independent binding of T $\beta I / T \beta R I I$ to T $\beta$ RIII competed with T $\beta I / T \beta R I I$ signaling complex formation, thus inhibiting TGF- $\beta$-mediated Smad signaling (15). Importantly, the alteration of T $\beta$ RIII expression level and the mediating roles have been observed in the progression of several types of cancers including breast, prostate, lung and ovarian cancer (16-19). Furthermore, the anchorage-independent growth of human MCF-7 breast cancer cells was inhibited when T $\beta$ RIII expression was recovered in vitro (20), and suppression of tumorigenicity occurred in MDA-MB231 breast cancer cells after increased T $\beta$ RIII expression in athymic nude mice (21). The expression level of $\mathrm{T} \beta \mathrm{RIII}$ and its regulatory role in HCC progression remain to be clarified.

Therefore, in the present study, we investigated the expression of T $\beta R I I I$ at both the mRNA and protein levels in HCC patient tissues and cell lines. In vitro, we also studied the regulatory roles of T $\beta$ RIII in metastasis and invasion of HCC and the related mechanisms.

\section{Materials and methods}

HCC patient tissues. Quantitative real-time PCR (qRT-PCR) and western blotting were utilized to examine the expression of T $\beta R I I I$ at the mRNA and protein level, respectively, in 10 HCC tissue specimens, which were collected at the First Affiliated Hospital of Anhui Medical University. All of the tissue specimens were pathologically confirmed as primary hepatic carcinoma and were promptly placed into sterile vials, and stored at $-80^{\circ} \mathrm{C}$ until required. Tissue collection was approved by the Ethics Committee of Anhui Medical University. All procedures involving specimens obtained from human subjects were performed following informed consent from the patients.

Cell culture. Human HCC cell lines with stepwise metastatic potential (HepG2, SMMC-7721, MHCC97H, HCCLM3) and the normal immortalized liver cell line L02 were cultured in Dulbecco's modified Eagle's medium (DMEM), supplemented with $10 \%(\mathrm{v} / \mathrm{v})$ fetal bovine serum (FBS) (both from Gibco, Life Technologies, USA) and $100 \mathrm{U} / \mathrm{ml}$ of penicillin and $100 \mu \mathrm{g} / \mathrm{ml}$ of streptomycin. Human normal liver L02 cells, and human HCC cell lines HepG2 and SMMC-7721 were purchased from Shanghai Cell Bank, Chinese Academy of Sciences (Shanghai, China). MHCC97H and HCCLM3 cells were purchased from Shanghai Institute of Biochemistry and Cell Biology, Chinese Academy of Science (Shanghai, China). All of the cell lines were maintained at $37^{\circ} \mathrm{C}$ in a $5 \% \mathrm{CO}_{2}$ atmosphere.

Quantitative real-time PCR ( $q R T$-PCR). qRT-PCR was carried out to examine the mRNA expression of T $\beta$ RIII. Glyceraldehyde 3-phosphate dehydrogenase (GAPDH) served as an internal control. Total RNA was extracted using TRIzol reagent (Invitrogen, Life Technologies, USA). Total RNA ( $2 \mu \mathrm{g})$ was reverse transcribed using the RevertAid First Strand cDNA Synthesis kit (Fermentas, Lithuania) according to the manufacturer's instructions. The detection was carried out in a real-time PCR detection system (ABI 7500) using the
SYBR-GreenER qPCR SuperMix Universal kit (Invitrogen, Life Technologies) according to the manufacturer's instructions. The primer sequences for each gene were: GAPDH forward primer, 5'-AGGTCGGAGTCAACGGATT TG-3' and reverse primer, 5'-CCTGGAAGATGGTGATGGG AT-3'; T $\beta$ RIII forward primer, 5'-ACCCCCAACTCTAACCC CTACA-3' and reverse primer, 5'-GCCAATACTGTTAGGAC AATAATTTTC-3'. The cycle threshold value was defined as the PCR cycle number at which the reporter fluorescence crosses the threshold. The cycle threshold value of each product was determined and normalized against that of the internal control, GAPDH.

TRRIII small interfering RNA (siRNA) transfection. According to the T $\beta$ RIII gene sequences, three siRNA duplexes targeting the T $\beta R I I I$ gene were designed (GenePharma, China): T $\beta$ RIIIhomo-2729 sense, 5'-GGGCCAUGAUGCAGAAUAATT-3' and antisense, 5'-UUAUUCUGCAUCAUGGCCCTT-3'; TRRIII-homo-2059 sense, 5'-GGUGUGGUCUACUAUAAC UTT-3' and antisense, 5'-AGUUAUAGUAGACCACACCTT-3'; TRRIII-homo-759 sense, 5'-GGUCACACUUCACCUGAAUT T-3' and antisense, 5'-AUUCAGGUGAAGUGUGACCTT-3'. The transfection operation was performed under guidance of the Lipofectamine 3000 protocol (Invitrogen, Life Technologies). The transfection efficiency was confirmed by western blotting.

Western blotting. Liver samples and human HCC cell lines were collected and cultured respectively, according to the methods described above. Liver tissue was homogenized in RIPA lysis buffer and phenylmethylsulfonyl fluoride (PMSF) at a ratio of 99:1 (v/v). The cells were washed twice with icecold phosphate-buffered saline (PBS) after the corresponding treatment and lysed in cell lysis buffer. The protein concentration was determined with the BCA protein assay kit (Thermo Fisher Scientific, USA). A protein sample was mixed with $5 \mathrm{X}$ sample buffer (4:1) (Bio-Rad, Hercules, CA, USA) and heated in boiling water for $10 \mathrm{~min}$. The proteins were separated by $10 \%$ sodium dodecyl sulfate-polyacrylamide gel electrophoresis (SDS-PAGE), transferred to polyvinylidene fluoride (PVDF) membranes (Millipore, Bedford, MA, USA), and incubated with blocking buffer $(0.05 \%$ Tween-20 PBS with $5 \%$ non-fat milk) for $2 \mathrm{~h}$. Immunoblots were incubated with the indicated primary antibodies overnight at $4^{\circ} \mathrm{C}$, followed by the appropriate horseradish peroxidase-conjugated secondary antibody for $2 \mathrm{~h}$ at room temperature, and immunodetection was visualized by enhanced chemiluminescence (Pierce, Rockford, IL, USA) using hydrogen peroxide and luminol as substrates. Autoradiographs were scanned using ImageQuant LAS 4000 mini (GE Healthcare Bio-Sciences AB, Uppsala, Sweden). The density of the specific bands was quantified using ImageJ software (National Institutes of Health, Bethesda, MD, USA).

Wound healing assay. SMMC-7721 cells were seeded in a 6-well plate at $70-90 \%$ confluency and the cell monolayer was scraped in a straight line to create a 'scratch' with a P200 pipette tip. The debris was removed and the edge of the scratch was smoothed by washing the cells twice with $1 \mathrm{ml}$ PBS. Then, $2 \mathrm{ml}$ serum-free DMEM was added with different 
A

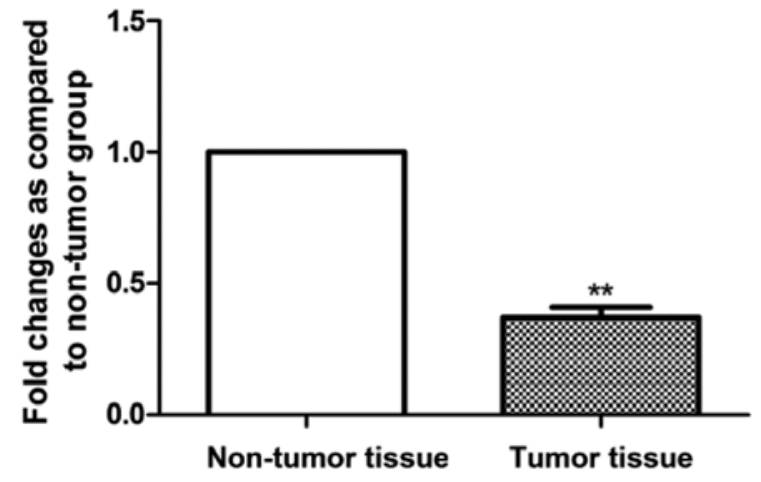

B
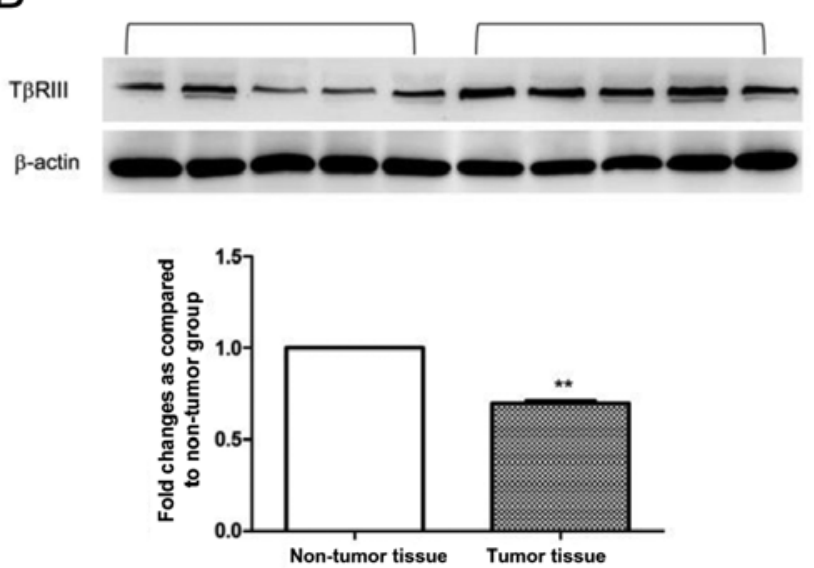

Figure 1. Expression of T $\beta$ RIII in tumor and non-tumor tissues of HCC patients. (A) The T $\beta$ RIII mRNA levels in tumor and non-tumor tissues were assayed by qRT-PCR. (B) The protein expression of T $\beta$ RIII in tumor and non-tumor tissues was assayed by western blotting. The quantitative analysis results shown in the histograms were calculated as fold-change relative to the non-tumor group that was assigned a value of 1 . The data are shown as means $\pm \mathrm{SD}$. ${ }^{* *} \mathrm{P}<0.01$ compared with the non-tumor group.

concentrations of TGF- $\beta 1(0.2,1,5$ and $25 \mathrm{ng} / \mathrm{ml})$ and images were captured using a computer-based microscopic imaging system at the $0 \mathrm{~h}$ time point at a magnification of x200. After $24 \mathrm{~h}$, images of the wound were captured again under magnification of $\mathrm{x} 200$.

Changes in the migratory ability of the human SMMC7721 cells after transfection with T $\beta$ RIII siRNA were also assessed by wound healing assay. SMMC-7721 cells were seeded to $70-90 \%$ confluency and starved for $12 \mathrm{~h}$. T $\beta$ RIII siRNA was transfected into the SMMC-7721 cells under the guidance of the Lipofectamine 3000 protocol. After $12 \mathrm{~h}$, the wound was created using the same method as described above. Images at 0 and $24 \mathrm{~h}$ were captured by a computerbased microscopy imaging system under a magnification of $\mathrm{x} 200$, respectively. Cell motility was evaluated according to the following formula: Cell motility ratio $=($ distance $24 \mathrm{~h}-$ distance $0 \mathrm{~h}) /$ distance $0 \mathrm{~h}$.

Transwell assay. SMMC-7721 cells plated in 6-well plates previously transfected with the T $\beta$ RIII siRNA for $12 \mathrm{~h}$ were harvested by trypsinization. The cells were washed once with PBS to remove the influence of FBS and then the cell pellet was resuspended in serum-free DMEM at $1 \times 10^{6}$ cells $/ \mathrm{ml}$. The cells $(25,000-50,000)$ were seeded in the upper chamber of a Transwell filter, coated with Matrigel (BD Biosciences) in order to determine the cell invasive ability. The cells were cultured for $48 \mathrm{~h}$ at $37^{\circ} \mathrm{C}$ in a $5 \% \mathrm{CO}_{2}$ incubator through Matrigel toward the lower chamber, containing medium with $10 \%$ FBS as the chemoattractant. After incubation, the medium in the upper chamber was discarded and then the upper chamber was removed gently from the 24 -well plates. The filter was fixed in $90 \%$ alcohol for $30 \mathrm{~min}$ and hexamethyl pararosaniline staining for $5 \mathrm{~min}$. Images were captured of representative fields of each filter, and the number of cells was quantified.

Statistical analysis. All data are expressed as means \pm SD. Statistical analysis was performed using one-way ANOVA. Statistical calculations were conducted using SPSS 10.0 soft- ware. The results were considered statistically significant for P-value $<0.05$.

\section{Results}

Decreased expression of T $\beta$ RIII in HCC patient tissues. To investigate whether T $\beta$ RIII expression is altered in HCC patient specimens, we initially analyzed the mRNA expression level in 10 human HCC tissue samples and compared the level with the matched non-tumor tissue samples as normal controls by qRT-PCR. From all the specimens, we observed a significant decrease in T $\beta$ RIII mRNA expression in tumor tissues compared with the matched non-tumor tissue samples (Fig. 1A). To confirm decreased expression of T $\beta$ RIII in HCC patient tissues, we examined T $\beta$ RIII expression at the protein level by western blot analysis. The result showed that the protein expression of T $\beta$ RIII was significantly decreased in the HCC tumor tissues compared with the level in the matched non-tumor tissue samples (Fig. 1B). The results revealed the impaired expression of T $\beta$ RIII at both the mRNA and protein level.

Decreased expression of T $\beta$ RIII in human HCC cell lines along with increased metastatic potential. To further confirm the alteration in the expression in T $\beta$ RIII in HCC progression, human liver L02 cells and four HCC cell lines with stepwise metastatic potential (HepG2, SMMC-7721, MHCC97H and HCCLM3) were selected to observe the expression change of T $\beta$ RIII in vitro by western blotting. Western blot results demonstrated the highest expression level in human liver L02 cells, while the expression of T $\beta$ RIII was gradually decreased with increasing metastatic potential in the HCC cell lines. Moreover, the expression of T $\beta$ RIII in the HCC cell lines MHCC97H and HCCLM3 which possess high metastatic potential was markedly lower than that in the HepG2 cells, an HCC cell line with low metastatic potential (Fig. 2). These results showed that a reduction in the expression of T $\beta$ RIII occurred simultaneously with the increasing metastatic potential of the HCC cells. 
A

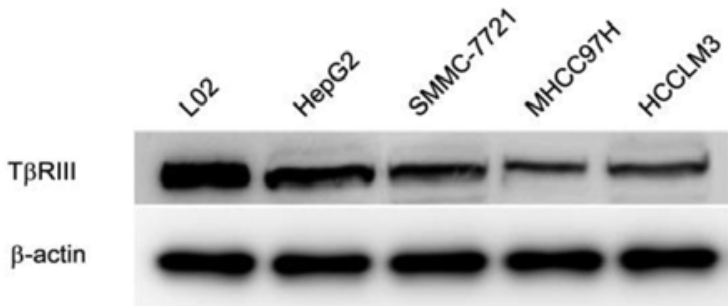

$\mathrm{B}$

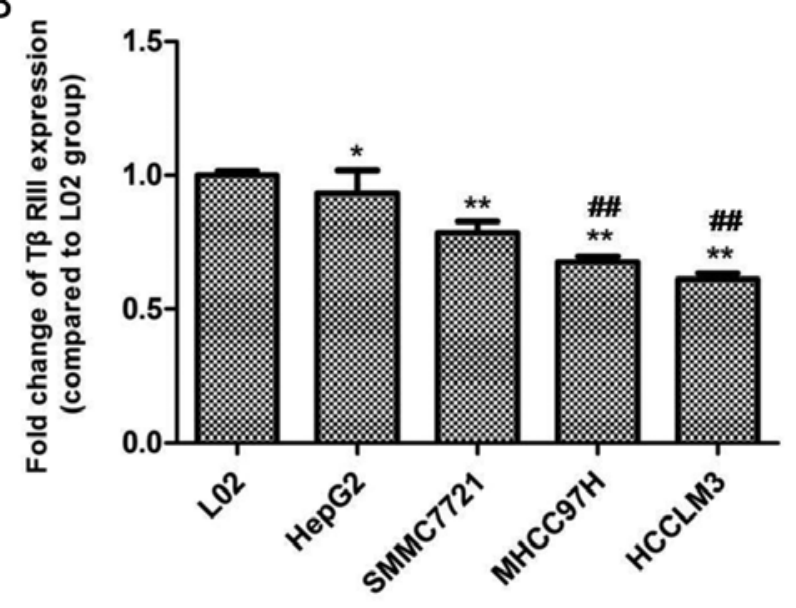

Figure 2. Expression of T $\beta$ RIII in HCC cell lines with different metastatic potential. (A) The expression level of T $\beta$ RIII in HCC cell lines by western blotting. (B) The quantitative analysis of T $\beta$ RIII expression is shown. The histogram results were calculated as fold-change relative to the L02 group that was assigned a value of 1 . The data are shown as means $\pm \mathrm{SD}$ and the results shown are representative of at least three independent experiments. ${ }^{*} \mathrm{P}<0.05,{ }^{* *} \mathrm{P}<0.01$ compared with the L02 group, ${ }^{\# \#} \mathrm{P}<0.01$ compared with the HepG2 group.

A
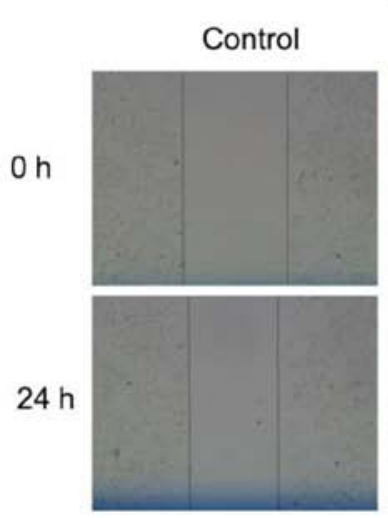
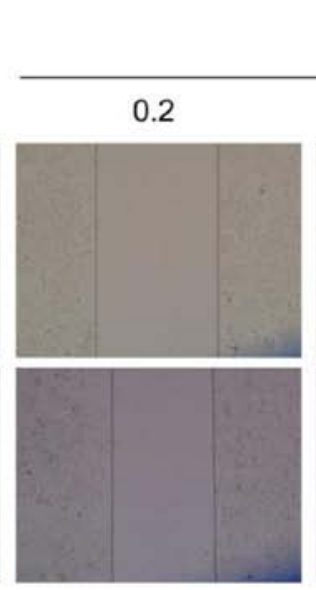

B

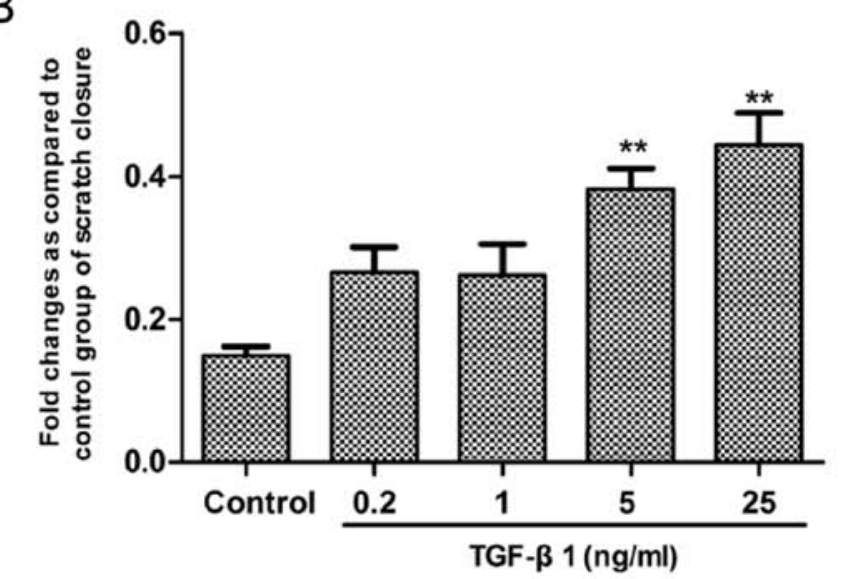

Figure 3. Effects of TGF- $\beta 1$ on the migration of SMMC-7721 cells. (A) Representative images of the wound healing assay results. (B) Histogram representing changes in the migratory ability of SMMC-7721 cells following stimulation with TGF- $\beta 1(0.2,1,5 \mathrm{and} 25 \mathrm{ng} / \mathrm{ml})$. The cell motility ratio of the control group was assigned as a value of 1 . Cell motility was evaluated according to the following formula: Cell motility ratio $=($ distance $24 \mathrm{~h}-\mathrm{distance} 0 \mathrm{~h}) / \mathrm{distance} 0 \mathrm{~h}$. The data are shown as means $\pm \mathrm{SD}$. ${ }^{* *} \mathrm{P}<0.01$ compared with the control group.

TGF- $\beta 1$ treatment enhances the migratory ability of human $H C C$ cell lines. TGF- $\beta 1$ is overexpressed and involved in the regulation of the progression of various types of cancer, and we investigated the effect of TGF- $\beta 1$ on the migratory ability 
A

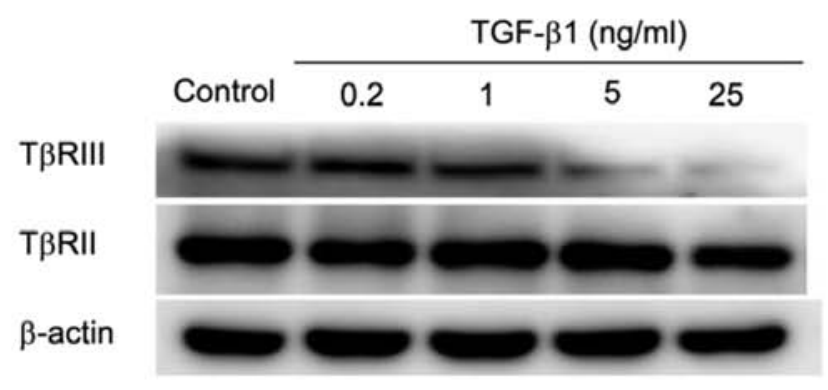

B

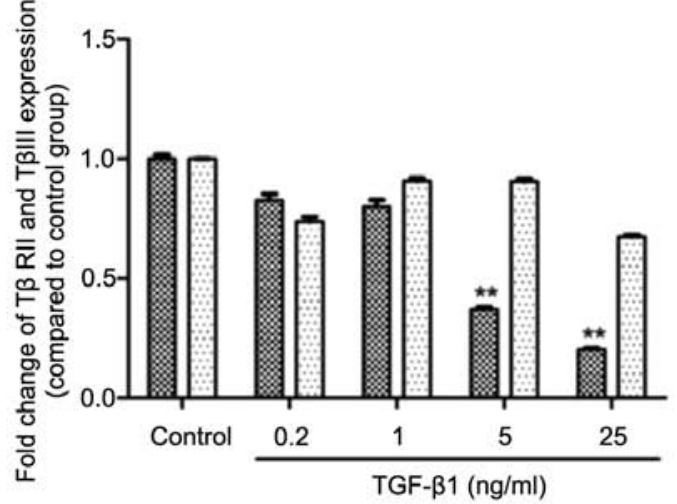

Figure 4. Expression levels of T $\beta$ RII and T $\beta$ RIII in TGF- $\beta 1$-stimulated SMMC-7721 cells. (A) SMMC-7721 cells were incubated for $24 \mathrm{~h}$ with TGF- $\beta 1$ and total cell lysates were prepared for analysis by western blotting to detect T $\beta$ RII and T $\beta$ RIII expression levels. (B) Quantitative analysis is shown as fold-change compared with the control group that was assigned a value of 1 . The data are shown as means \pm SD. The results shown are representative of at least three independent experiments. ${ }^{* *} \mathrm{P}<0.01$ compared with the control group.

of human HCC cells. Human SMMC-7721 cells were seeded in a 6 -well plate $\left(5 \times 10^{5}\right.$ cells/well) and starved for $12 \mathrm{~h}$ on the following day. Then, SMMC-7721 cells were exposed to TGF- $\beta 1$ for $24 \mathrm{~h}$ at concentrations of $0.2,1,5$ and $25 \mathrm{ng} / \mathrm{ml}$. The wound healing assay showed that TGF- $\beta 1$ significantly elevated the migratory ability of the SMMC-7721 cells in a concentration-dependent manner, particularly in the 5 and $25 \mathrm{ng} / \mathrm{ml}$ treatment groups (Fig. 3). The results indicated that TGF- $\beta 1$ promoted the metastasis of the HCC cells.

TGF- $\beta 1$ stimulation reduces the expression of T $\beta$ RIII in human HCC cells. To further characterize the effect of TGF- $\beta 1$ on the expression of T $\beta$ RIII, we treated human SMMC-7721 cells with TGF- $\beta 1$ at stepwise concentrations $(0.2,1,5$ and $25 \mathrm{ng} /$ $\mathrm{ml}$ ) and assessed the protein level of T $\beta$ RIII using western blotting. Treatment with TGF- $\beta 1$ ( 5 and $25 \mathrm{ng} / \mathrm{ml}$ ) resulted in a significantly decreased expression level of the T $\beta$ RIII protein (Fig. 4). To assess whether the effects of TGF- $\beta 1$ on T $\beta$ RIII were specific, we analyzed the effect of TGF- $\beta 1$ on T $\beta$ RII expression. Western blot results showed no significant changes in the level of T $\beta$ RII expression upon TGF- $\beta 1$ treatment at various concentrations (Fig. 4). The results above indicated that it was T $\beta$ RIII instead of T $\beta$ RII that was downregulated by TGF- $\beta 1$ in the human SMMC-7721 cells.

Decreased expression of TRRIII elevates the migratory and invasive abilities of human HCC cells. We detected the gradually decreased expression of T $\beta$ RIII in human HCC cell lines along with increasing metastatic potential. To investigate the roles of T $\beta$ RIII in regulating the migratory and invasive abilities of the HCC cells, we silenced the expression of T $\beta$ RIII by transfection of siRNA targeting the T $\beta$ RIII gene. The wound healing and Transwell assays were performed to detect the migratory and invasive abilities of the SMMC-7721 cells transfected with the siRNA targeting T $\beta$ RIII, respectively. The wound healing assay results revealed that the migratory ability of the SMMC-7721 cells in the siRNA transfection groups was significantly increased compared with the corresponding control groups (Fig. 5). The Transwell assay showed a significantly increased invasive ability of the SMMC-7721 cells in the
siRNA transfection groups compared with the corresponding control groups (Fig. 6). Collectively, these results confirmed that the downregulation of T $\beta$ RIII expression promoted HCC cell migration and invasion in vitro.

Silencing of TRRIII expression by siRNA activates the Smad2 and Akt pathways in the SMMC-7721 cells. TGF- $\beta 1$ was found to promote the migration of HCC cells and reduced the expression of T $\beta$ RIII, and furthermore, silencing of the expression of T $\beta$ RIII elevated the migration and invasion abilities of the HCC cells. Thus, we hypothesized that the inhibitory effects of T $\beta$ RIII on migration and invasion of HCC cells may be through regulation of the TGF- $\beta$ downstream signaling pathway. Therefore, to further confirm this hypothesis, we examined Smad 2 and Akt activation by western blotting after transfection of T $\beta$ RIII siRNA. The results revealed that silenced expression of T $\beta$ RIII in the siRNA transfection groups increased the expression levels of $\mathrm{p}-\operatorname{Smad} 2$ and $\mathrm{p}-\mathrm{Akt}$ compared with the corresponding control groups (Fig. 7).

\section{Discussion}

The three highly homologous isoforms of TGF- $\beta$ in humans (TGF- $\beta 1$, TGF- $\beta 2$ and TGF- $\beta 3$ ) share a receptor complex and signal in similar ways while their expression levels vary depending on the tissue (22). TGF- $\beta$ can induce an epithelialmesenchymal transition (EMT) of both epithelial and endothelial cells, which contributes to disease progression in both cancer and fibrosis (23). EMT promotes cellular migratory and invasion properties, as cellular migration requires the loss of cell-cell contacts and acquisition of fibroblastic characteristics. Several studies have demonstrated the increased expression of TGF- $\beta 1$ in various types of cancers and the close association with tumor metastasis, invasion and the poor prognosis of patients $(24,25)$. Although the increased expression of TGF- $\beta 1$ has been reported to be closely associated with a poor prognosis and tumor angiogenesis in HCC (26-28), the mechanism concerning the role of the promotion of tumorigenesis remains unclear. The research based on the MDA-MB-231 breast cancer and Ovca420 ovarian cancer cells in vitro revealed 
A

NC

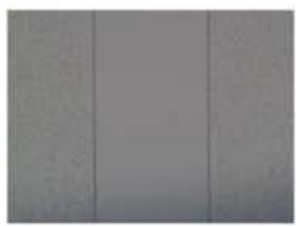

$\mathrm{Oh}$

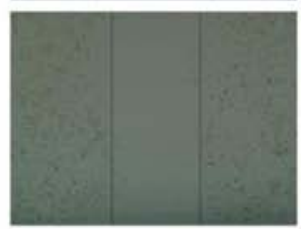

Control
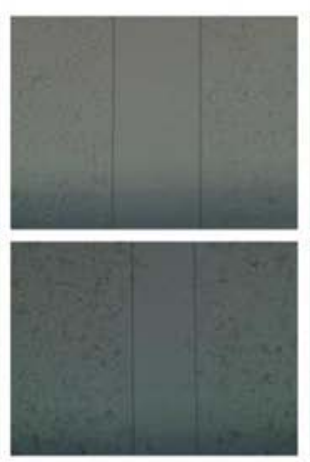

B
TGF- $\beta 1$
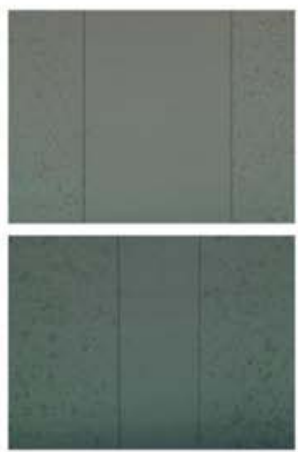

si T $\beta R I I I+T G F-\beta 1$
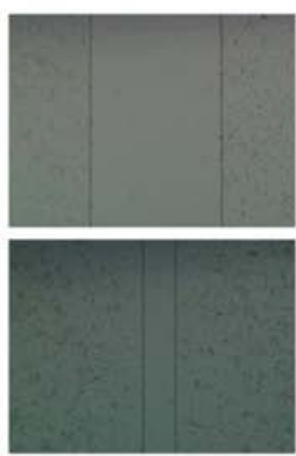

si TRRIII
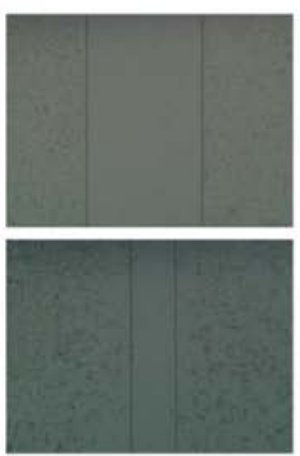

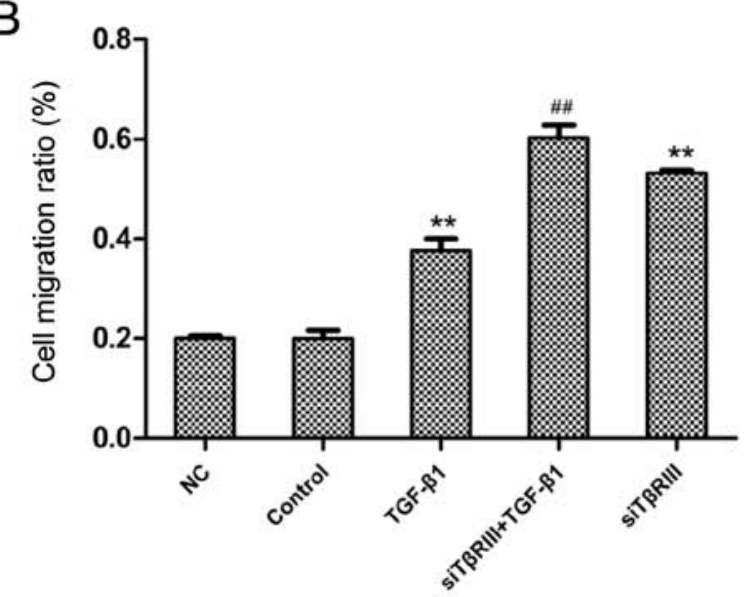

Figure 5. Effects of T $\beta$ RIII siRNA on the migration of SMMC-7721 cells. (A) The migratory ability was assessed by wound healing assay. (B) Histogram shows the effects of transfection on migratory ability. Cell motility was evaluated according to the following formula: Cell migration ratio $=($ distance $24 \mathrm{~h}-$ distance $0 \mathrm{~h}$ )/distance $0 \mathrm{~h}$. The data from three independent experiments are shown as the mean \pm SD. NC, negative control; siT $\beta R I I I, T \beta R I I I$ siRNA. ${ }^{* *} \mathrm{P}<0.01 \mathrm{com}-$ pared with the control group; ${ }^{\# \#} \mathrm{P}<0.01$ compared with the TGF- $\beta 1$ group.

A $\mathrm{NC}$

Control TGF- $\beta 1$

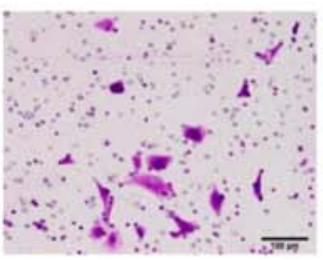

B

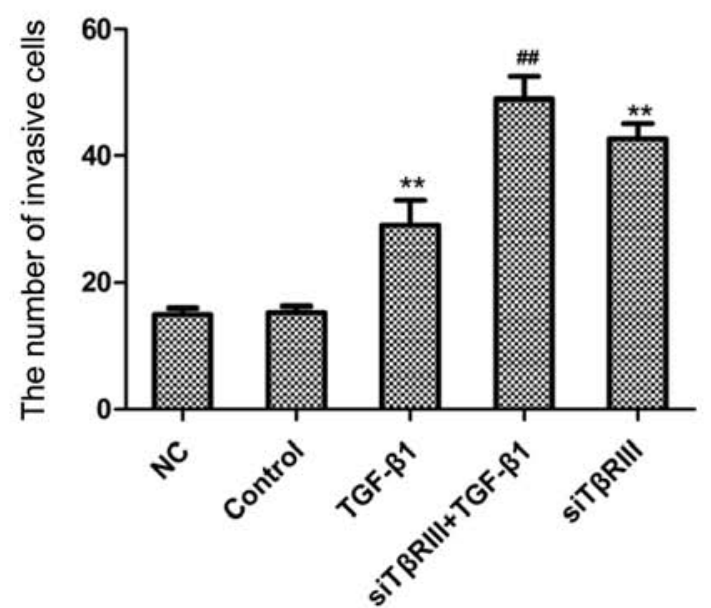

Figure 6. Effects of T $\beta$ RIII siRNA on the invasive ability of SMMC-7721 cells. (A) The invasive ability was assessed by Transwell invasion assay. (B) Histogram shows the effects of transfection on invasion ability. The data from three independent experiments are shown as the mean \pm SD. NC, negative control; siT $\beta R I I I$, T $\beta$ RIII siRNA. ${ }^{* *} \mathrm{P}<0.01$ compared with the control group; ${ }^{\# \#} \mathrm{P}<0.01$ compared with the TGF- $\beta 1$ group. 
A

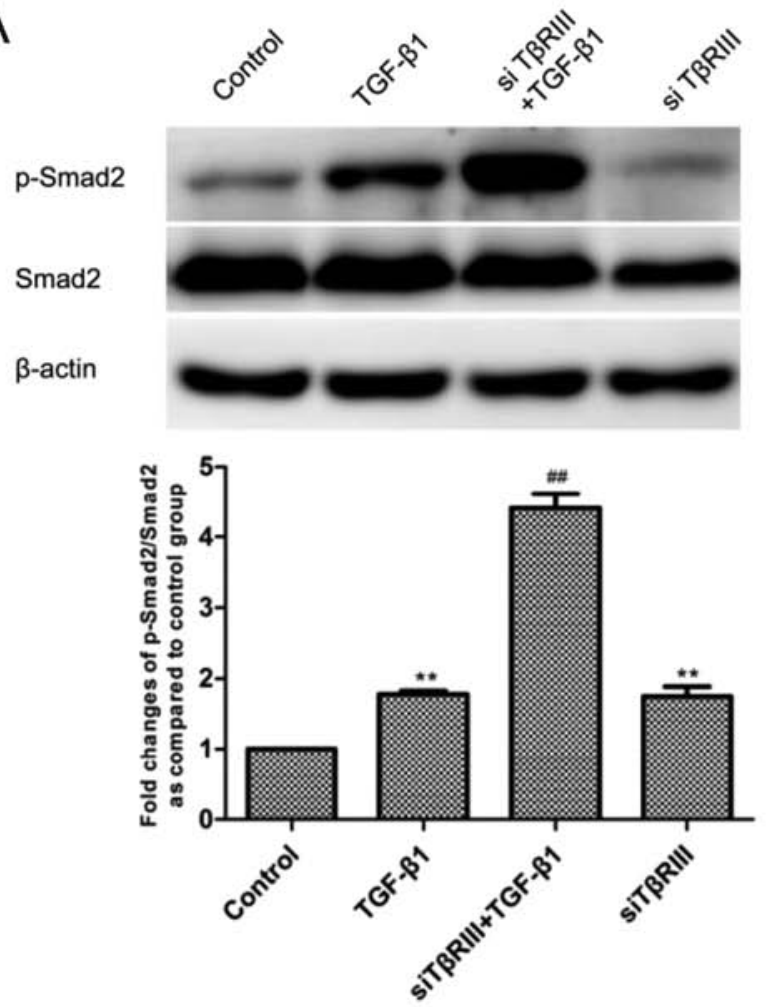

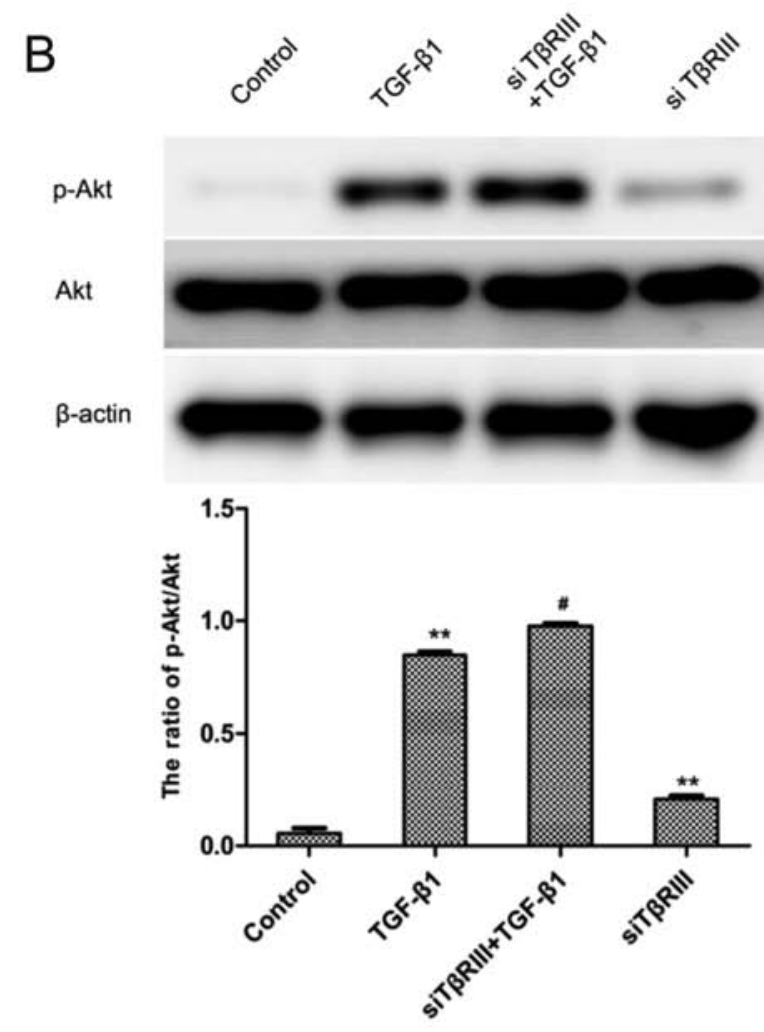

Figure 7. Effects of T $\beta$ RIII siRNA transfection on activation of the Smad2 and Akt pathways in SMMC-7721 cells. Low expression of T $\beta$ RIII resulted in the increased activation levels of Smad2 (A) and Akt (B). The semi-quantitative analysis is shown as a histogram. The results were calculated as fold-change relative to the control group, which was assigned as a value of 1 . siT $\beta$ RIII, T $\beta$ RIII siRNA. ${ }^{* *} \mathrm{P}<0.01$, compared with the control group; ${ }^{\# \mathrm{P}}<0.05$, ${ }^{\# \#} \mathrm{P}<0.01$ compared with the TGF- $\beta 1$ group.

that TGF- $\beta 1$ reduced the expression of T $\beta$ RIII at the mRNA and protein levels in a dose- and time-dependent manner (29). In our previous study, we established an HCC animal model by intraperitoneally injecting diethylinitrosamine (DEN) in 14-day-old C57BL/6J mice. The results revealed significantly increased expression of TGF- $\beta 1$ and induced activation of Smad2 signaling in a time-dependent manner after the injection (30). In the present study, we observed that TGF- $\beta 1$ promoted the migratory ability and induced decreased expression of T $\beta$ RIII in HCC cells. These results suggest that the TGF- $\beta 1$ expression level may be a diagnostic predictor of HCC progression, and its promotive effect on the migration of HCC cells may be associated with the low expression of T $\beta$ RIII.

The negative regulation of T $\beta$ RIII expression by TGF- $\beta 1$ may provide insight into the tumor-promoting effects of elevated TGF- $\beta 1$ and the role of decreased T $\beta$ RIII expression in HCC as well. The expression level of TGF- $\beta 1$ was found to be elevated and correlated with the migration and invasion in a spectrum of human cancers $(24,25)$. Nevertheless, the mechanism by which the high level of TGF- $\beta 1$ exerts tumorpromoting effects remains unclear. A recent study found that T $\beta$ RIII inhibited TGF- $\beta$-mediated signaling through the independent binding to T $\beta R I$ and T $\beta R I I$ and competition with $T \beta R I / T \beta R I I$ complex formation (15). We found decreased expression of T $\beta$ RIII concomitant with the elevated level of TGF- $\beta 1$, as well as the role of TGF- $\beta 1$ in promoting metastasis in the HCC cell lines. Thus, the present study confirmed decreased T $\beta$ RIII expression as a possible mechanism for the tumor-promoting role of TGF- $\beta 1$.
TGF- $\beta$ binds to the constitutively active type II TGF- $\beta$ receptor (T $\beta$ RII) along with the consequent activation of the type I TGF- $\beta$ receptor (T $\beta R I)$, subsequently forming heteromeric complexes to induce downstream signaling transduction $(9,12)$. Although lacking intrinsic enzymatic activity, T $\beta R I I I$ is the most abundantly expressed TGF- $\beta$ superfamily receptor and has a complex- and contextdependent role in regulating TGF- $\beta$ superfamily signaling and cancer progression with mechanisms yet to be defined. Recently, the decreased and even lost expression of T $\beta$ RIII have been reported in several types of cancers including breast, prostate, lung and ovarian cancer (16-19). Several studies have also demonstrated the aberrant expression of T $\beta$ RIII in HCC $(27,31)$. However, the specific expression condition and roles of T $\beta$ RIII in HCC development and progression require further research. The results of the present study showed that the expression of T $\beta R I I I$ in human HCC tissues was significantly decreased compared with the level in the matched normal liver tissues, at the mRNA and protein levels. In our previous study of an animal model, we also found that the expression of T $\beta$ RIII was decreased in DEN-induced HCC mice compared with normal control mice along with increasing time after DEN injection (30). These results suggest that the decreased expression of T $\beta$ RIII has a negative regulatory role in $\mathrm{HCC}$ progression.

Notably, the regulatory roles of T $\beta$ RIII in inhibiting tumor invasion, angiogenesis, and metastasis have also been defined. The restoration of T $\beta R I I I$ expression in murine mammary cancer cells and prostate cancer cells inhibited 
tumor invasion, angiogenesis, and metastasis both basally and in response to TGF- $\beta$ treatment in vivo and in vitro, respectively $(16,17,21,32)$, and expression of T $\beta$ RIII inhibited the motility and invasion of NSCLC cells and knockdown of T $\beta$ RIII expression increased its invasion (18). To further investigate the roles of T $\beta$ RIII in the regulation of HCC migration and invasion, we performed research using human HCC cell lines in vitro. Consistently, the results showed that gradually decreased expression of T $\beta$ RIII was observed in HCC cell lines along with increasing metastatic potential. Human normal liver L02 cells showed the highest expression level of T $\beta$ RIII protein, while the MHCC97H and HCCLM3 cell lines with high metastatic potential exhibited a markedly lower expression level than that in HepG2, an HCC cell line with low metastatic potential. Based on the findings of decreased T $\beta$ RIII expression in HCC cell lines with increasing metastatic potential, we hypothesized that T $\beta$ RIII may be a negative regulator of the migration and invasion of HCC. In addition, the results of siRNA targeting of the T $\beta$ RIII gene revealed that knockdown of T $\beta$ RIII led to the enhanced motility and invasiveness of human SMC-7721 cells both basically and under TGF- $\beta 1$ stimulation. Collectively, based on the results in HCC patient tissues and in a previous HCC mouse model (30), we propose that low expression of T $\beta$ RIII is involved in the malignant progression of $\mathrm{HCC}$, and T $\beta$ RIII plays a suppressive role in regulating the metastasis and invasion of HCC.

T $\beta$ RIII has been previously found to exert inhibitory effects on the migration and invasion of HCC and on various types of cancers; however, the related mechanisms remain to be defined. T $\beta$ RIII has been shown to have effects on both the Smad and non-Smad signaling pathways in a liganddependent or -independent manner, including the Smad, $\mathrm{NF}-\kappa \mathrm{B}$ and p38 signaling pathways (33-35). In mouse lung fibroblasts, the expression of T $\beta$ RIII was found to reduce the phosphorylation of Smad2, Smad3 and Akt (36). Moreover, it has been reported that restoration of T $\beta$ RIII in breast cancer inhibited the expression level of Smad 2 or Smad3 in vivo and in vitro (16). In our previous study in an HCC mouse model, we detected that the expression of $\mathrm{p}-\mathrm{Smad} 2$ was elevated in a time-dependent manner, meanwhile the TGF- $\beta 1$ level was increased (30). In the present study, we detected the expression of p-Smad 2 and p-Akt in SMMC-7721 cells after transfection with T $\beta$ RIII siRNA. The results revealed that the expression levels of p-Smad2 and p-Akt were elevated in the siRNA groups compared with the corresponding control groups. These results suggest that T $\beta$ RIII suppressed the progression of HCC by inhibiting the activation of Smad2 and Akt pathways, and subsequently decreasing the migration and invasion of HCC.

In conclusion, T $\beta$ RIII displayed decreased expression with HCC progression in vivo and in vitro, which may be associated with the higher level of TGF- $\beta 1$. An elevated level of TGF- $\beta 1$ and decreased expression of T $\beta$ RIII may lead to the activation of Smad2, and the mechanism between them is yet to be defined. Furthermore, T $\beta$ RIII acts as a suppressive factor in regulating the migration and invasion of $\mathrm{HCC}$, by inhibiting the Smad 2 and Akt pathways. The present study confimed that T $\beta$ RIII may be a candidate molecular target in HCC diagnosis and treatment.

\section{Acknowledgements}

The present study was financially supported by the National Natural Science Foundation of China (nos. 81300332 and 81330081), the Specialized Research Fund for the Doctoral Program of Higher Education of China (no. 20113420120002), and the Natural Science Foundation of the Higher Education Institutions of Anhui Province (no. KJ2012A153). The authors acknowledge the assistance of the staff members of the Institute of Clinical Pharmacology, Anhui Medical University, in conducting the present study.

\section{References}

1. Torre LA, Bray F, Siegel RL, Ferlay J, Lortet-Tieulent J and Jemal A: Global cancer statistics, 2012. CA Cancer J Clin 65: 87-108, 2015.

2. Buendia MA and Neuveut C: Hepatocellular carcinoma. Cold Spring Harb Perspect Med 5: a021444, 2015.

3. Radeleff BA, Stampfl U, Sommer CM, Bellemann N, Hoffmann K, Ganten T, Ehehalt R and Kauczor HU: Transarterial ablation of hepatocellular carcinoma. Status and developments. Radiologe 52: 44-55, 2012 (In German).

4. Lencioni R and Crocetti L: Local-regional treatment of hepatocellular carcinoma. Radiology 262: 43-58, 2012.

5. de Lope CR, Tremosini S, Forner A, Reig M and Bruix J: Management of HCC. J Hepatol 56 (Suppl 1): S75-S87, 2012.

6. Schmierer B and Hill CS: TGFbeta-SMAD signal transduction: Molecular specificity and functional flexibility. Nat Rev Mol Cell Biol 8: 970-982, 2007.

7. Akhurst RJ and Hata A: Targeting the TGF $\beta$ signalling pathway in disease. Nat Rev Drug Discov 11: 790-811, 2012.

8 . Zhang S, Sun WY, Wu JJ and Wei W: TGF- $\beta$ signaling pathway as a pharmacological target in liver diseases. Pharmacol Res 85: 15-22, 2014.

9. Derynck R and Zhang YE: Smad-dependent and Smadindependent pathways in TGF-beta family signalling. Nature 425: 577-584, 2003.

10. López-Casillas F, Cheifetz S, Doody J, Andres JL, Lane WS and Massagué J: Structure and expression of the membrane proteoglycan betaglycan, a component of the TGF-beta receptor system. Cell 67: 785-795, 1991.

11. Wang XF, Lin HY, Ng-Eaton E, Downward J, Lodish HF and Weinberg RA: Expression cloning and characterization of the TGF-beta type III receptor. Cell 67: 797-805, 1991.

12. Shi Y and Massagué J: Mechanisms of TGF-beta signaling from cell membrane to the nucleus. Cell 113: 685-700, 2003.

13. Thatcher JD: The TGF-beta signal transduction pathway. Sci Signal 3: $\operatorname{tr} 4,2010$.

14. Li D, Xu D, Lu Z, Dong X and Wang X: Overexpression of transforming growth factor type III receptor restores TGF- $\beta 1$ sensitivity in human tongue squamous cell carcinoma cells. Biosci Rep 35: 35, 2015.

15. Tazat K, Hector-Greene M, Blobe GC and Henis YI: T $\beta$ RIII independently binds type I and type II TGF- $\beta$ receptors to inhibit TGF- $\beta$ signaling. Mol Biol Cell 26: 3535-3545, 2015.

16. Dong M, How T, Kirkbride KC, Gordon KJ, Lee JD, Hempel N, Kelly P, Moeller BJ, Marks JR and Blobe GC: The type III TGF-beta receptor suppresses breast cancer progression. J Clin Invest 117: 206-217, 2007.

17. Turley RS, Finger EC, Hempel N, How T, Fields TA and Blobe GC: The type III transforming growth factor-beta receptor as a novel tumor suppressor gene in prostate cancer. Cancer Res 67: 1090-1098, 2007.

18. Finger EC, Turley RS, Dong M, How T, Fields TA and Blobe GC: TbetaRIII suppresses non-small cell lung cancer invasiveness and tumorigenicity. Carcinogenesis 29: 528-535, 2008.

19. Hempel N, How T, Dong M, Murphy SK, Fields TA and Blobe GC: Loss of betaglycan expression in ovarian cancer: Role in motility and invasion. Cancer Res 67: 5231-5238, 2007.

20. Chen C, Wang XF and Sun L: Expression of transforming growth factor beta (TGFbeta) type III receptor restores autocrine TGFbeta1 activity in human breast cancer MCF-7 cells. J Biol Chem 272: 12862-12867, 1997. 
21. Sun $L$ and Chen $C$ : Expression of transforming growth factor beta type III receptor suppresses tumorigenicity of human breast cancer MDA-MB-231 cells. J Biol Chem 272: 25367-25372, 1997.

22. Millan FA, Denhez F, Kondaiah P and Akhurst RJ: Embryonic gene expression patterns of TGF beta 1, beta 2 and beta 3 suggest different developmental functions in vivo. Development 111: 131-143, 1991.

23. Derynck R and Akhurst RJ: Differentiation plasticity regulated by TGF-beta family proteins in development and disease. Nat Cell Biol 9: 1000-1004, 2007.

24. Huang AL, Liu SG, Qi WJ, Żhao YF, Li YM, Lei B, Sheng WJ and Shen H: TGF- $\beta 1$ protein expression in non-small cell lung cancers is correlated with prognosis. Asian Pac J Cancer Prev 15: 8143-8147, 2014.

25. Chen K, Wei H, Ling S and Yi C: Expression and significance of transforming growth factor- $\beta 1$ in epithelial ovarian cancer and its extracellular matrix. Oncol Lett 8: 2171-2174, 2014.

26. Ji GZ, Wang XH, Miao L, Liu Z, Zhang P, Zhang FM and Yang JB: Role of transforming growth factor-beta1-smad signal transduction pathway in patients with hepatocellular carcinoma. World J Gastroenterol 12: 644-648, 2006.

27. Abou-Shady M, Baer HU, Friess H, Berberat P, Zimmermann A, Graber H, Gold LI, Korc M and Büchler MW: Transforming growth factor betas and their signaling receptors in human hepatocellular carcinoma. Am J Surg 177: 209-215, 1999.

28. Tsai JF, Chuang LY, Jeng JE, Yang ML, Chang WY, Hsieh MY, Lin ZY and Tsai JH: Clinical relevance of transforming growth factor-beta 1 in the urine of patients with hepatocellular carcinoma. Medicine 76: 213-226, 1997.

29. Hempel N, How T, Cooper SJ, Green TR, Dong M, Copland JA, Wood CG and Blobe GC: Expression of the type III TGF-beta receptor is negatively regulated by TGF-beta. Carcinogenesis 29: 905-912, 2008.
30. Zhang S, Sun WY, Gu YJ and Wei W: The expression of type III TGF- $\beta$ receptor in diethylnitrosamine-induced liver cancer model. Acta Univ Medicinalis Anhui 50: 912-916, 2015 (In Chinese).

31. Bae HJ, Eun JW, Noh JH, Kim JK, Jung KH, Xie HJ, Park WS Lee JY and Nam SW: Down-regulation of transforming growth factor $\beta$ receptor type III in hepatocellular carcinoma is not directly associated with genetic alterations or loss of heterozygosity. Oncol Rep 22: 475-480, 2009.

32. Sharifi N, Hurt EM, Kawasaki BT and Farrar WL: TGFBR3 loss and consequences in prostate cancer. Prostate 67: 301-311, 2007.

33. You HJ, How T and Blobe GC: The type III transforming growth factor-beta receptor negatively regulates nuclear factor kappa B signaling through its interaction with beta-arrestin2. Carcinogenesis 30: 1281-1287, 2009.

34. Criswell TL and Arteaga CL: Modulation of NFkappaB activity and E-cadherin by the type III transforming growth factor beta receptor regulates cell growth and motility. J Biol Chem 282: 32491-32500, 2007.

35. Margulis V, Maity T, Zhang XY, Cooper SJ, Copland JA and Wood CG: Type III transforming growth factor-beta (TGF-beta) receptor mediates apoptosis in renal cell carcinoma independent of the canonical TGF-beta signaling pathway. Clin Cancer Res 14: 5722-5730, 2008.

36. Ahn JY, Park S, Yun YS and Song JY: Inhibition of type III TGF- $\beta$ receptor aggravates lung fibrotic process. Biomed Pharmacother 64: 472-476, 2010. 